\title{
Dietary Fats and Metabolic Syndrome
}

\author{
Danijela Ristic-Medic* and Vesna Vucic \\ Centre of Research Excellence in Nutrition and Metabolism, Institute for medical research, University of Belgrade, Serbia
}

Received: November 27, 2013; Accepted: December 20, 2013; Published: December 28, 2013

*Corresponding author: Danijela Ristic-Medic, Centre of Research Excellence in Nutrition and Metabolism, Institute for Medical research, University of Belgrade, Serbia, Tel: 381-30-31-997; Fax: 381-11-2030169; E-mail: dristicmedic@gmail.com

\begin{abstract}
The quantity and quality of fats consumed in the diet can have important effects on prevention and/or improvement clustering metabolic abnormalities of the metabolic syndrome. Fatty acids as food ingredients regulate cholesterol homeostasis and concentrations of blood lipoproteins, and affect the levels of other cardiometabolic risk factors, such as blood pressure, haemostasis, and body weight, through various mechanisms. There is convincing evidence that exchanging dietary saturated fat with monounsaturated fat produces beneficial effects on metabolic control, i.a. it lowers LDL-cholesterol concentrations, improves the postprandial lipid profile and lowers the blood pressure. Serum fatty acid composition mainly reflects dietary fat intake, but also endogenous fatty acid synthesis catalyzed by desaturases. Furthermore, high fat intake and serum fatty acid profile may influence the progression of obesity and insulin sensitivity. This review highlights current dietary guidance of fats quality recommendation in health and cardio metabolic risk.
\end{abstract}

Keywords: Dietary fats; Plasma triglycerides; Cholesterol; Diabetes

\section{Abbreviations}

AA: Arachidonic Acid; ALA: Alfa-Linolenic Acid; ATP: Adult Treatment Panel; BP: Blood Pressure; CVD: Cardiovascular Disease; CRP: C - reactive protein; DGLA: Dihomo- $\gamma$-Linolenic Acid; DHA: Docosahexaenoic Acid; DPA: Docosapentaenoic Acid; EFA: Essential Fatty Acids; EPA: Eicosapentaenoic Acid; FA: Fatty Acid; GLA -Gama-Linolenic Acid; HDL: High Density Lipoprotein; IL: Interleukine; IR: Insulin Resistance; LA: Linoleic Acid; LDL: Low Density Lipoprotein; LC: Long Chain; LT: Leukotrienes; MetS: Metabolic Syndrome; MUFA: Monounsaturated Fatty Acid; NCEP: National Cholesterol Education Program; PAI-1 : Plasminogen Activator Inhibitor-1; PG: Prosta Glandins; PPAR : Peroxisome Proliferation Activator Receptor; PUFA: Polyunsaturated Fatty Acid; SFA: Saturated Fatty Acid; TFA: Trans Fatty Acid; TGF: Transforming growth Factor; TNF: Tumor Necrosis Factor; TX: Thromboxanes; VLDL: Very Low Density Lipoprotein.

\section{Introduction}

Metabolic syndrome (MetS), which has a high prevalence worldwide, refers to a cluster of metabolic abnormalities including disturbances in glucose and insulin metabolism, central obesity, dyslipidemia (high triglyceride levels, low HDL (high-density lipoprotein)-cholesterol and high levels of small dense LDL-particles) and hypertension. Other disturbances often associated with MetS include impaired fibrinolysis and increased coagulation, signs of inflammation and endothelial dysfunction [1]. These metabolic abnormalities are well-documented risk factors for cardiovascular disease (CVD) and type 2 diabetes.

Dietary fat is a mixture of fatty acids (FA), with saturated (SFA), trans-unsaturated (TFA), monounsaturated (MUFA) and polyunsaturated FA (PUFA) as the main components. PUFAs are further classified as n-3 and n- 6 PUFAs which have different health effects. Fatty acid composition in the diet plays an important role in modifying several key factors of MetS [2,3]. Namely, epidemiologic and experimental studies have shown that plasma FA profiles are related to insulin sensitivity, blood pressure, plasma lipid profile and inflammation, which are all involved in depelopment of MetS [4-7]. Furthermore, FA profile of serum/plasma phospholipids is mostly influenced by the dietary intake during the last 6-8 weeks [8-10]. The most important FA in terms of MetS modulation are the long-chain (LC)-PUFAs of $\mathrm{n}-3$ series. Among them, docosahexaenoic acid (DHA; C22:6n-3) and eicosapentaenoic acid (EPA; $\mathrm{C} 20: 5 n-3)$ have been shown to decrease triacylglycerols levels, increase HDL-cholesterol levels in plasma, prevent the development of heart disease and exert anti-inflammatory properties in humans reviewed in Ristic Medic, et al. [11]. They are both abundant in seafood. Increased dietary intake of oily fish or supplementation with fish oil have beneficial effect on several features of MetS. There is convincing evidence that exchanging dietary saturated fat with monounsaturated fat produces beneficial effects on cardiovascular disease risk i.e., It lowers LDL-cholesterol concentrations [12], improves the postprandial lipid profile [13], and lowers the blood pressure [14]. Therefore the aim of the present review is to summarize the role of dietary fats in the prevention and treatment of the Mets.

\section{Diagnostic criteria for MetS and optimal diet}

There are no well-accepted criteria for the diagnosis MetS. Metabolic syndrome is usually defined according to the criteria of the NCEP Adult Treatment Panel III as the presence in an individual of at least three of the following risk factors:

i. Abdominal obesity (waist circumference $>102 \mathrm{~cm}$ for men and $>88 \mathrm{~cm}$ for women) 


\section{ii. High triglycerides levels ( $\geq 150 \mathrm{mg} / \mathrm{dL}$ )}

iii. Low HDL- cholesterol levels ( $<40 \mathrm{mg} / \mathrm{dL}$ in men or $<50$ $\mathrm{mg} / \mathrm{dL}$ in women)

iv. High blood pressure ( $\geq 130 / 85 \mathrm{~mm} \mathrm{Hg}$ on at least two separate measurements)

v. High fasting glucose $\geq 100 \mathrm{mg} / \mathrm{dL}$ ( $\geq 5.6 \mathrm{mmol} / \mathrm{L}$ ) [1].

The ATP III panel did not find adequate evidence to recommend routine measurement of insulin resistance (e.g., plasma insulin), proinflammatory state (e.g., high-sensitivity C-reactive protein), or prothrombotic state (e.g., fibrinogen or PAI-1) in the diagnosis of the metabolic syndrome. As MetS is characterized by numerous factors, it is very difficult to establish a correct diagnosis and adequate therapy. Central to the etiology of MetS is an interrelated triad comprising inflammation, obesity (particularly abdominal), and aberrations in fatty acid metabolism $[15,16]$.

Medical nutrition therapy should start with dietary assessment, including the patient's motivational level and willingness to change. Changes in dietary habits, hypocaloric diets, increased physical activity and weight loss (reduction) usually improve levels of LDL cholesterol, glycemic levels, and blood pressure and have the potential to improve long term metabolic control $[1,17]$. It was proposed that optimal diet for the treatment of MetS should be limited in the intake of saturated fat, while some flexibility might be allowed in the amount of fat and carbohydrate, e.g. exchanging about $10 \%$ energy between monounsaturated fat and carbohydrate-rich foods with high glycemic index (GI) [2]. It is recommended that about $45 \%$ of the energy intake must be distributed between unsaturated fat and high-GI carbohydrate, while high fiber /low-GI foods should be used without specific limitations [1,2]. Thus, high-GI starchy foods could be set at $25 \%$ energy and monounsaturated fat at $20 \%$ energy (plus polyunsaturated fat, which is generally recommended not to exceed $10 \%$ energy). Since monounsaturated fats do not cause adverse metabolic effects, moderate amounts of these fats are allowed in daily intake. Findings of an adverse impact of total fat intake and protection of PUFAs concerning the association with metabolic syndrome are supported by several investigations [18]. Fatty acids as food ingredients regulate cholesterol homeostasis and concentrations of blood lipoproteins, and affect the levels of other cardiovascular risk factors, such as blood pressure, haemostasis, and body weight, through various mechanisms.

\section{Dietary fats, dyslipidemia and MetS}

Epidemiological studies have shown that the population who consume large amounts of saturated, atherogenic FA (especially those of 12-16 carbon: palmitic, myristic, lauric) have elevated levels of LDL-cholesterol [19]. Saturated FA exert their atherogenic and thrombogenic effect through increased production of very low-density lipoproteins (VLDL)-particles and Apo A1, with a decrease of LDL- receptors specific activity, and an increase in platelet aggregation [20]. Unlikely other SFAs, stearic acid (18:0) showed no atherogenic or thrombogenic effect, since after absorption it is desaturated to monounsaturated oleic acid (18:1), which is associated with beneficial effect on cardiovascular health. Oleic acid is incorporated into phospholipids rather than into triglycerides and cholesterol esters. Moreover, stearic acid showed similar reducing effect on platelet aggregation and coagulation factors as the unsaturated oleic and linoleic acids [21].

However, the highest atherogenic potential have trans fatty acids (TFA), which are obtained from partial hydrogenation of plant oils. Thus industrial foods - cakes, cookies and crackers often contain a high content of TFA. They lead to an increase in total and LDL-cholesterol, as well as highly atherogenic lipoprotein (a), and lower levels of HDL-cholesterol [22,23]. Due to these effects, TFA are more atherogenic when compared to SFA.

In contrast to TFA and SFA, monounsaturated fats are neutral in terms to atherogenicity. Commonly present MUFAs in the diet is oleic acid, which is found mostly in olive (56-84 \%) and rapeseed oil [24]. Replacing SFA in the diet with oleic acid have been shown to lower plasma cholesterol [25]. Large intake of olive oil is typical for Mediterranean countries. Studies conducted in this region showed that intake of olive oil moderately lowered total and LDL-cholesterol, slightly increased HDL-cholesterol and had no significant effect on blood triglycerides [26,27]. Furthermore, this FA increased the activity of LDL-receptors and reduced the LDL-particle peroxidation. In spite of favourable effects on cardiovascular health, it should be noticed that plant oils rich in MUFAs are highly energy-dense, and diet based on a large intake of these oils could lead over time to obesity.

A meta-analysis of 60 controlled trials reported that replacement of carbohydrates with PUFAs (largely n-6) had a positive effect on the total cholesterol/HDL-cholesterol ratio, and on LDL levels [28]. In line with this, Perunicic-Pekovic et al. [29] have recently found that plasma total cholesterol negatively correlated with plasma levels of EPA. Reduction of total and LDL-cholesterol blood levels, as well as of the total cholesterol/ HDL-cholesterol ratio was also reported when dietary n-6 PUFAs intake achieved 5 to $20 \%$ of the energy intake [30]. The metabolic benefit could be even stronger when PUFAs exchange SFA in the diet [31,32]. According to the study by Clarke et al. [31], replacement of 6-4 \% of energy intake as SFA by n-6 PUFAs while keeping total fat content at 30-33\% of energy, led to a reduction of $0.64 \mathrm{mmol} / \mathrm{l}$ in plasma LDL-cholesterol.

Since triglycerides are also a risk factor for cardiovascular disease and one of the metabolic abnormalities in MetS, their reduction by the diet is also very important for maintaining health. A number of studies have demonstrated significant lowering effects of triglyceride levels by intake/supplementation of n-3 PUFAs in patients with cardio metabolic risk [33]. A meta-analysis of 72 randomized control trials [34] reported even $25 \%$-30 \% reduction of serum triglycerides with a dosage of 3-4 g/day of EPA + DHA. The hypolipidemic effect of n-3 PUFAs primarily results due to a decrease in lipogenesis, lower formation of triacylglycerols, and their lower release as VLDLs into circulation [35]. 
Furthermore, n-3 PUFAs could modify gene expression altering levels of lipids in blood, by activating expressions of genes involved in the $\beta$-oxidation, which are controlled by the PPAR- $\alpha$ receptors [36,37]. Another mechanism involves decreased the fractional catabolic rates of HDL and increased ratio of HDL2/HDL-3 cholesterol after fish oil supplementation [38]. This was related to the decrease in levels of plasma triglycerides; HDL particles become larger, retain more cholesterol and are less susceptible to catabolism by hepatic and renal clearance pathways [39].

\section{Dietary fats, insulin resistance and MetS}

Insulin resistance (IR) is markedly affected by the amount and composition of dietary fats [18]. Amount is particularly important, since excessive intake of total fat ( $>37 \%$ of daily energy intake) independently on the FA composition, may worse IR [3]. Although underlyining mechanism is still unclear, it likely includes interference with binding of insulin to its receptors and accumulation of triglycerides in skeletal muscle [40]. On the other hand, if total fat intake does not exceede $30 \%$, the type of FA consumed appears to differently influence IR [3]. Vessby, et al. [3] found that an exchange of saturated for monounsaturated fats in the diet improved insulin sensitivity. It has been shown with an intravenous glucose tolerance test, whereas no improvement in fasting insulin or insulin secretion was seen. Other studies reported that [41] a diet high in MUFAs improved glucose metabolism better than the officially recommended low-fat diet. It was shown that relatively higher intake of nuts and legumes (typical for a Mediterranean diet) are related to an improved fasting glucose level and may lead to a more favorable long-term glucose homeostasis. The mechanisms are unclear but there was some proposed effect of MUFAs on cell membrane [42], affecting membrane fluidity, ion permeability, insulin receptor affinity and up-regulation of glucose transporters [40].

In addition to MUFA, n-3 PUFAs supplementation has also been shown to improve insulin sensitivity, prevent alterations in glucose homeostasis and further development of diabetes type 2 [42-44]. Long chain PUFAs of n-3 series probably exert these effects through up-regulation of the PPARs, and in turn are related to the gene expression involved in lipid oxidation and synthesis [45]. Also, glucose uptake and utilization is increased by the intake of n-3 LC-PUFAs. The skeletal muscle are the key player in the insulin-sensitizing effect of $n-3$ PUFAs, since they are quantitatively the most important site of whole-body glucose utilization reviewed in Lombardo and Chicco [35].

\section{Dietary fats as modulators of adiposity and MetS}

Adipose tissues play the major role in the development of the MetS, probably by the secretion of mediators of inflammation. Thus, it is possible to alleviate obesity and MetS as its metabolic consequence by modulating the metabolism and secretory functions of AT. In line with this, studies in animals fed an high-fat diet reported beneficial effect of n-3 LC-PUFAs on the development of obesity and insulin resistance reviewed in Lombardo and Chicco. [35]. For instance, n-3 LC-PUFAs induce mitochondrial biogenesis and $\beta$-oxidation in adipocytes which leads to a decrease in adiposity. The correlation is especially strong between accumulation of body fat and diabetes, indicating the importance of AT metabolism and adipokines derived by AT in the development MetS [46,47].

Furthermore, some studies suggested that n-6 PUFA may be involved in the differentiation of preadipose cells to adipocytes but available in vitro and animal studies have not supported such effect of n-6 PUFAs [48-50]. However, increments in insulin sensitivity may be more directly related to loss of intramyocellular or omental fat rather than loss of total body weight per se. Further research is needed to investigate the possible contribution of dietary n-3/n-6 ratio to development of excessive adipose tissue.

\section{Dietary fats, inflamation and MetS}

As in many other chronic non-communicable diseases, lowgrade inflammation is at the base of MetS. Low grade inflammation is characterised by relatively small (2-3 fold) increase of lipid and peptid inflammatory mediators in circulation (e.g. eicosanoids and cytokines) than in the physiological conditions. Since eicosanoids are derived from 20 carbon PUFAs (mostly EPA and arachidonic acid-AA, 20:4n-6), their synthesis is affected by the dietary intake of these FA. Thus the role of PUFAs in modulation of inflammatory response has been extensively investigated [51] and reviewed [52].

Eicosanoids are signaling molecules which includes prostaglandins (PG), leukotrienes (LT) and thromboxanes (TX). All of them play role in inflammation acting proinflammatory (for instance $\mathrm{PGE}_{2}$ and $\left.\mathrm{LTB}_{4}\right)$ or anti-inflammatory $\left(\mathrm{LTB}_{5}, \mathrm{LTE}_{5}, \mathrm{PGE}_{3}\right)$. Proinflammatory eicosanoids are mostly derived from AA via cyclooxigenase and lipoxigenase-5 enzymatic pathways, while EPA is precursor for most of the anti-inflammatory eicosanoids, competing for the same enzymes [53] (Figure 1). Furthermore, in the presence of different eicosanoids, human leukocytes produce different cytokines, depending on the type of the signal. Human monocytes exposed to leukotrienes (e.g. $\mathrm{LTB}_{4}$ ) release high amounts of tumor necrosis factor (TNF)- $\alpha$ [54]. In contrast, $\mathrm{PGE}_{2}$ strongly inhibited the release of TNF- $\alpha$ by macrophages [55]. An enhancing role of leukotrienes on production of IL-1 and IL- 6 was also documented [56].

Many of the cytokines are associated with MetS. Several studies $[57,58]$ have documented direct role of circulating TNF- $\alpha$ in insulin resistance and metabolic syndrome. High levels of TNF- $\alpha$ were also found in people with type 2 diabetes. In addition, abdominal fat, which is one of the component of MetS, is assigned as a possible origin of TNF- $\alpha$. There are some evidence of the involvement of IL- 6 in MetS, but the data are inconsistent.

The beneficial effect of $n-3$ PUFAs supplementation on inflammation markers have been shown in many studies. Animal studies have demonstrated inhibited production of proinflammatory cytokines IL-1 and TNF after fish oil intervention [59]. Similar observations were reported in studies in humans. Dietary supplementation with n-3 PUFAs in healthy subjects was associated with reduced levels of IL-1, thromboxane 2, and PGE2, [60] and lower production of pro-inflammatory cytokines IL-1, 


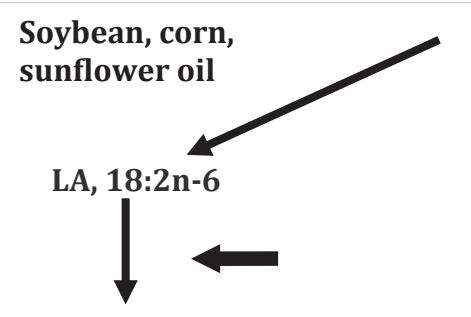

GLA, 18:3n-6

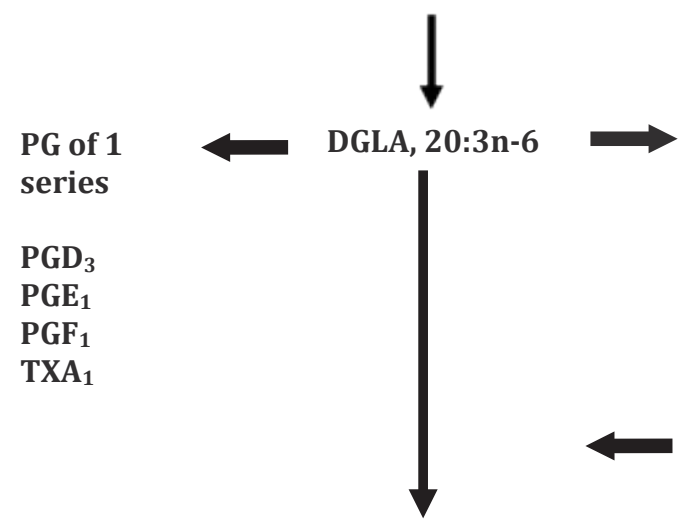

AA, 20:4n-6

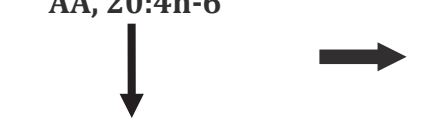

Cyclooxygenase enzymes

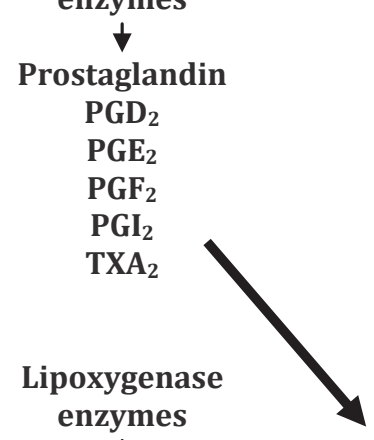

$\downarrow$

Leukotriene

LTA $_{4}$

$\mathrm{LTB}_{4}$

$\mathrm{LTC}_{4}$

$\mathrm{LTD}_{4}$

$\mathrm{LTE}_{4}$
Diet

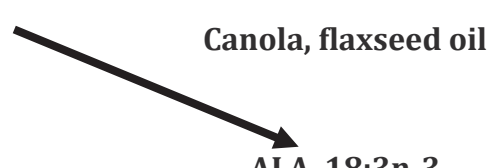

$\Delta 6$-desaturase

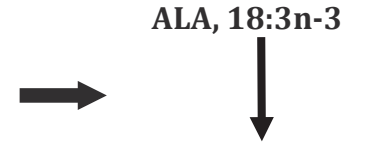

$18: 4 n-3$

Leukotriene

series

$\mathrm{LTA}_{3}$

$\mathrm{LTC}_{3}$

$\mathrm{LTD}_{3}$

\section{$\Delta 5$-desaturase}

EFFECT

Obesogenic diet +n-3 LC-PUFA

Positive effect on peripheral insulin

response tissues

(ß-cells, liver, skeletal muscle)
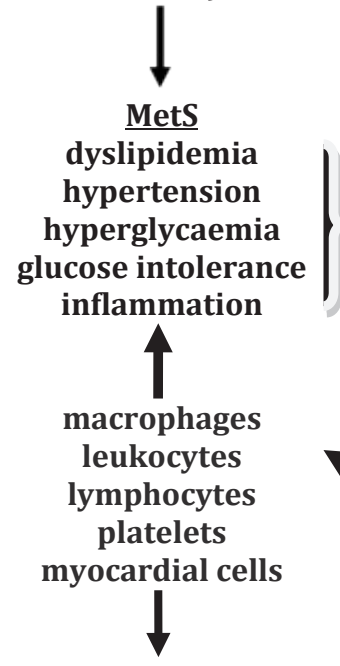

Type 2 diabetes

Cardiovascular

disease

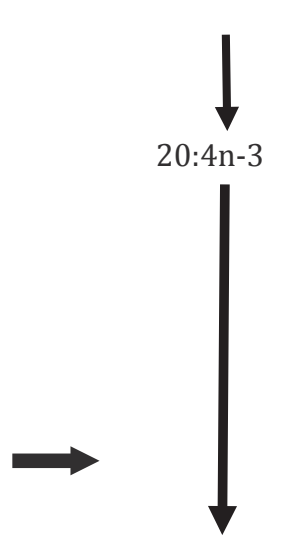

Cold water fish

(EPA+DHA)

EPA, 20:5n-3

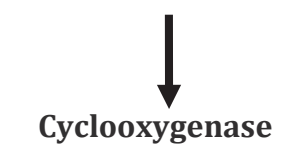

enzymes

Prostaglandin

$\mathrm{PGD}_{3}$

$\mathrm{PGE}_{3}$

$\mathrm{PGF}_{3}$

$\mathrm{PGI}_{3}$

$\mathrm{TXA}_{3}$

$\mathrm{TXB}_{3}$

\section{Lipoxygenase} enzymes

$\downarrow$

Leukotriene

LTA $_{5}$

LTB $_{5}$

LTC $_{5}$

LTD $_{5}$

$\mathrm{LTE}_{5}$

Figure 1: Dietary sources, metabolism of n-3 and n-6 PUFAs and clustering metabolic abnormalities of the metabolic syndrome.

Sourse: Ristic-Medic et al. Poly unsaturated fatty acid in health and disease. J Serb Chem Soc 2013; 78:1269-1289 (modified with written permission of the publisher)

Legend: AA -arachidonic acid; ALA - $\alpha$-linolenic acid; DGLA -dihomo- $\gamma$-linolenic acid; DHA -docosahexaenoic acid; GLA - $\gamma$-linolenic acid; EPA -eicosapentaenoic acid; LA- linoleic acid; LT -leukotrienes; PG -prostaglandins; TX -thromboxanes 
IL-6, TNF- $\alpha$ and TNF- $\beta$ in response to an inflammatory stimulus [52]. Additionally, relative concentration of PUFA in plasma were independently associated with lower levels of proinflammatory markers (IL-6, IL-1ra, TNF- $\alpha$, CRP) and higher levels of antiinflammatory markers (soluble IL-6r, IL-10, TGF- $\beta$ ) in 1123 persons aged 20-98 years [61]. Taking into account all these data, it is clear that PUFAs have an important role in inflammation and MetS. While n-6 PUFAs act proinflammatory, n-3 PUFAs reduce inflammation, which is involved in pathogenesis of MetS. Therefore, dietary intervention with n-3 PUFAs is recommended in people with MetS. Unlikely PUFAs, there is no evidence on the relationship between dietary SFAs or MUFAs and inflammation.

\section{Dietary fats, blood pressure and MetS}

Changing the proportions of dietary fat by decreasing SFAs and increasing MUFAs decreased diastolic blood pressures (BP). As highlighted by a review of cross-sectional studies, an increase in the dietary intake of n- 6 PUFAs is often associated with a decrease in BP pressure as well [62]. The beneficial effect on BP which is a component of MetS induced by fat quality was negated by the consumption of a high total fat intake ( $>37 \%$ of energy). Plasma levels of LA were inversely associated with systolic and diastolic BPs [63]. Meta-analysis by Morris et al. [64] found a dose-response hypotensive effect of $5.6 \mathrm{~g}$ n-3 PUFAs on, systolic and diastolic BP, which was reduced by 3.4 and $2.0 \mathrm{mmHg}$ respectively in hypertensive patients. Dietary fats may modulate BP through different mechanisms. Possible mechanisms include modulation of the biosynthesis of eicosanoids: hydroxy eicosatetraenoates or epoxy eicosatrienoates $[11,65]$. PUFAs n-6 and n-3 are converted to prostaglandins, which reduce BP by affecting arterial vasodilation, electrolyte balance, and renal release of renin or pressor hormones. Another meta-analysis also supported the antihypertensive effects of n-3 PUFAs but that seem to be a small dose-dependent, hypotensive effect, dependent on the degree of hypertension $[14,66]$. Animal models and cell culture studies indicate that n-3 PUFAs supplementation can lower BP and proteinuria, potentially by the vasorelaxation action of $n-3$ PUFAs with increased endothelium-derived releasing factor and having effects on TGF- $\beta$, renin, fibronectin and nitric oxide synthesis [67].

\section{Biomarker fatty acids, estimated desaturase activities and MetS}

As mentioned above, FA profile in serum/plasma lipids mirrors the dietary fatty acid composition over the proceeding weeks $[8,6,68]$. It has been postulated that biomarker FAs and estimated desaturase activities are independent risk factors in the development of MetS. In addition to dietary intake, metabolic processes and desaturation or elongation of ingested FA influence FA profile in plasma phospholipids and cholesterol esters. Estimated activities of desaturase/ elongase system are determined as certain fatty acid indexes: $20: 4 / 20: 3$ ratio is used as a measure of delta $(\Delta) 5$ desaturase, the $20: 3 / 18: 2$ ratio is a measure of $\Delta 6$ desaturase, while $16: 1 / 16: 0,18: 1 / 18: 0$ and 18:0/16:0 ratios represent estimated $\Delta 9$ desaturase- 1 and -2 and elongase activities respectively [69]. Studies on animal suggested a key role $\Delta 9-1$ desaturase in obesity related metabolic diseases, while $\Delta 5$ desaturase activity has been positively associated with insulin action $[70,71]$. Several studies have indicated the involvement of $\Delta 9-1$ in the metabolic effects of PUFAs in the liver and skeletal muscle, where PUFAs down-regulate the $\Delta 9$ - 1 gene [71]. $\Delta 9-1$ desaturase is a central lipogenic enzyme, catalysing the synthesis of MUFAs both in the liver and skeletal muscle [70].

Biomarker FA, estimated desaturase activities and FA involved in development of metabolic and cardiovascular diseases can be used as biomarkers of dietary fat intake and therefore as the exposure variable in epidemiological studies of the association between dietary fat and disease outcome [72]. For instance, $\Delta 9$ desaturase- $1(16: 1 / 16: 0)$ is valuable marker of dietary saturated fat [73], but has also been established as an independent predictor of directly measured insulin sensitivity [70]. Further, SFA proportion in serum phospholipids can predict the development of MetS. High proportions of palmitic (16:0), palmitoleic (16:1) and dihomo-gama-linolenic (20:3 n-6, DGLA) acids and a low proportion of LA, have been associated with insulin resistance, obesity, CVD and type 2 diabetes and MetS $[4,5,72,74,75]$. Kim et al. [7] have recently concluded that the reduced activity of $\Delta 5$ desaturase and increased proportion of DGLA and DGLA/LA ratio in individuals with more risk factors for MetS development, indicated that altered FA metabolism may induce the accumulation of DGLA, possibly as a consequence of long-term metabolic disorders i.e. obesity and IR. Elevated proportions of LA in plasma phospholipids decreased the risk of fasting glycemia and type 2 diabetes in middle-aged men, while depressed levels of DHA is related increased CVD risk [76]. Moreover, increased estimated activities of $\Delta 9$ and $\Delta 6$ desaturase and reduced $\Delta 5$ desaturase have also been related to metabolic and cardiovascular diseases.

\section{Conclusion}

The failure to maintain the optimal FA composition of plasma lipids and cell membranes and synthesis of vasoactive and proinflammatory eicosanoids are the main causes of MetS. These findings reveal an important role of FA and their metabolites in the pathogenesis of the MetS. It is evident that diet rich in SFA induces the same serum FA acid pattern as that seen in individuas with MetS. High fat intake and unfavorable FA composition in dietary fats may influence the progression of obesity and insulin sensitivity. Mediterranean-like dietary pattern, avoiding excess intake of dietary fat and substituting SFA and TFA by MUFA and n-6 PUFAs, results in better insulin sensitivity. Moreover, FA composition of sserum phospholipids and estimated desaturase activity correlate with a number of MetS risk factors. Dietary guidelines to limit consumption of total fat and saturated fat as one way to reduce the cardio metabolic risk of abnormal plasma lipids, hypertension, insulin resistance, diabetes and obesity, suggested that diet-based approaches may be suitable target for prevention and treatment of the MetS.

\section{Acknowledgements}

This study was supported by the Project III 41030 financed by the Ministry of Science of the Republic of Serbia. 


\section{References}

1. National Cholesterol Education Program (NCEP) Expert Panel on Detection E, and Treatment of High Blood Cholesterol in Adults (Adult Treatment Panel III). Third report of the National Cholesterol Education Program (NCEP) expert panel on detection, evaluation and treatment of high cholesterol in adults (Adult Treatment Panel III) final report. Circulation 2002;106:3143-421.

2. Riccardi G, Rivellese AA (2000) Dietary treatment of the metabolic syndrome--the optimal diet. British Journal of Nutrition 83: S143-S148.

3. Vessby B, Unsitupa M, Hermansen K, Riccardi G, Rivellese AA, et al. (2001) Substituting dietary saturated for monounsaturated fat impairs insulin sensitivity in healthy men and women: The KANWU Study. Diabetologia 44(3): 312-319.

4. Wang L, Folsom AR, Zheng ZJ, Pankow JS, Eckfeldt JH (2003) Plasma fatty acid composition and incidence of diabetes in middle-aged adults: the Atherosclerosis Risk in Communities (ARIC) Study. The American Journal of Clinical Nutrition 78(1): 91-98.

5. Tremblay AJ, Despres JP, Piche ME, Nadeau A, Bergeron J, et al. (2004) Associations between the fatty acid content of triglyceride, visceral adipose tissue accumulation, and components of the insulin resistance syndrome. Metabolism 53(3): 310-317.

6. Warensjo E, Riserus U, Vessby B (2005) Fatty acid composition of serum lipids predicts the development of the metabolic syndrome in men. Diabetologia 48(10): 1999-2005.

7. Kim OY, Lim HH, Lee MJ, Kim JY, Lee JH (2013) Association of fatty acid composition in serum phospholipids with metabolic syndrome and arterial stiffness. Nutrition, Metabolism \& Cardiovascular Diseases 23(4): 366-374.

8. Ma J, Folsom AR, Shahar E, Eckfeldt JH (1995) Plasma fatty acid composition as an indicator of habitual dietary fat intake in middleaged adults. The Atherosclerosis Risk in Communities (ARIC) Study Investigators. The American Journal of Clinical Nutrition 62(3): 564571.

9. Ristic-Medic D, Suzic S, Vucic V, Takic M, Tepsic J, et al. (2009) Serum and erythrocyte membrane phospholipid fatty acid composition in hiperlipidemia: effects of dietary intervention and combined diet and fibrate therapy. Gen Physiol Biophys 28: 190-199.

10. Tepsic J, Vucic V, Arsic A, Mladenovic VB, Mazic S, et al. (2009) Plasma and erythrocyte phospholipid fatty acid profile in professional basketball and football players. Eur J Appl Physiol 107(3): 359-365.

11. Ristic-Medic D, Vucic V, Takic M, Karadzic I, Glibetic M (2013) Polyunsaturated fatty acid in health and disease. J Serb Chem Soc 78: 1269-1289.

12. Rivellese AA, Maffettone A, Vessby B, Uusitupa M, Hermansen K, et al. (2003) Effects of dietary saturated, monounsaturated and n-3 fatty acids on fasting lipoproteins, LDL size and post-prandial lipid metabolism in healthy subjects. Atherosclerosis 167(1): 149-158.

13. Thomsen C, Rasmussen O, Lousen T, Holst JJ, Fenselau S, et al. (1999) Differential effects of saturated and monounsaturated fatty acids on postprandial lipemia and incretin responses in healthy subjects. Am J Clin Nutr 69(6): 1135-1143.

14. Rasmussen BM, Vessby B, Uusitupa M, Berglund L, Pedersen E, et al. (2006) Effects of dietary saturated, monounsaturated, and n-3 fatty acids on blood pressure in healthy subjects. Am J Clin Nutr 83(2): 221226.
15.Vessby B (2000) Dietary fat and insulin action in humans. Br J Nutr 83: S91-S96.

16. Takic M, Ristic-Medic D, Mandic Lj, Glibetic M, Arsic A, et al. (2009) N-3 polyunsaturated acids in erythrocyte phospholipids are associated with insulin sensitivity in obese patients on a typical Serbian diet. Arch Biol Sci Belgrade 61(1): 37-43.

17. Corpeleijn E, Feskens EJ, Jansen EH, Mensink M, Saris WH, et al. (2006) Improvements in glucose tolerance and insulin sensitivity after lifestyle intervention are related to changes in serum fatty acid profile and desaturase activities: the SLIM study. Diabetologia 49(10): 2392-2401.

18. Weickert MO (2012) What dietary modification best improves insulin sensitivity and why? Clin Endocrinol 77(4): 508-512.

19. Graham I, Atar D, Borch-Johnsen K, Boysen G, Burell G, et al. (2007) European guidelines on cardiovascular disease prevention in clinical practice: executive summary. Eur Heart J 28(19): 2375-2414.

20. Hunter JE, Zhang J, Kris-Etherton PM (2010) Cardiovascular disease risk of dietary stearic acid compared with trans, other saturated, and unsaturated fatty acids: a systematic review. Am J Clin Nutr 91: 46-63.

21. Thijessen MA, Hornstra G, Mensink RP (2005) Stearic, Oleic, and Linoleic Acids Have Comparable Effects on Markers of Thrombotic Tendency in Healthy Human Subjects. J Nutr 135(12): 2805-2811.

22. Brouwer IA, Wanders AJ, Katan MB (2013) Trans fatty acids and cardiovascular health: research completed? Eur J Clin Nutr 67(5): 541-547.

23. Booker CS, Mann JI (2008) Trans fatty acids and cardiovascular health: translation of the evidence base. Nutr Metab Cardiovasc Dis 18(6): 448-456.

24.Vucic V, Tepsic J, Arsic A, Popovic T, Debeljak-Martacic J, et al. (2012) Fatty acid content of vegetable oils and assessment of their consumption in Serbia. Acta Alimentaria 41(3): 343-350.

25.http://www.ehnheart.org/euroheart-ii/euroheart-ii-publications. html

26. Serra-Majem L, Roman B, Estruch R (2006) Scientific evidence of interventions using the Mediterranean diet: a systematic review. Nutr Rev 64: S27-47.

27. Mensink RP, Katan MB (1992) Effect of dietary fatty acids on serum lipid and lipoproteins. A meta-analysis of 27 trials. Arterioscl Thromb 12(8): 911-919.

28. Mensink RP, Zock PL, Kester AD, Katan MB (2003) Effects of dietary fatty acids and carbohydrates on the ratio of serum total to HDL cholesterol and on serum lipids and apolipoproteins: a meta-analysis of 60 controlled trials. Am J Clin Nutr 77(5): 1146-1155.

29. Perunicic-Pekovic G, Rasic-Milutinovic Z, Gluvic Z, Lackovic M, RisticMedic D, et al. (2012) Inflammation, nutritional status, PUFA profile and outcome in hemodialysis patients. Arch Biol Sci Belgrade 64(3): $1173-1180$.

30. Jakobsen MU, O’Reilly EJ, Heitmann BL, Pereira MA, Balter K, et al. (2009) Major types of dietary fat and risk of coronary heart disease: a pooled analysis of 11 cohort studies. Am J Clin Nutr 89(5): 1425-1432.

31. Clarke R, Frost C, Collins R, Appleby P, Peto R (1997) Dietary lipids and blood cholesterol: quantitative meta-analysis of metabolic ward studies. BMJ 314: 112-117.

32. Hodson L, Skeaff C, Chisholm WA (2001) The effect of replacing dietary 
saturated fat with polyunsaturated or monounsaturated fat on plasma lipids in free-living young adults. Eur J Clin Nutr 55(10): 908-915.

33. Krebs JD, Browning LM, McLean NK, Rothwell JL, Mishra GD, et al. (2006) Additive benefits of long-chain $n-3$ polyunsaturated fatty acids and weight-loss in the management of cardiovascular disease risk in overweight hyperinsulinaemic women. Int J Obes 30(10): 1535-1544.

34. Harris WS (1997) n-3 fatty acids and serum lipoproteins: human studies. Am J Clin Nutr 65: 1645S-1654S.

35. Lombardo YB, Chicco AG (2006) Effects of dietary polyunsaturated $\mathrm{n}-3$ fatty acids on dyslipidemia and insulin resistance in rodents and humans. A review. J Nutr Biochem 17(1): 1-13.

36. Lapillonne A, Clarke SD, Heird WC (2004) Polyunsaturated fatty acids and gene expression. Curr Opin Clin Nutr Metab Care 7(2): 151-156.

37. Davidson MH (2006) Mechanisms for the hypotriglyceridemic effect of marine omega-3 fatty acids. Am J Cardiol 98: 27i-33i.

38. Chan DC, Watts GF, Nguyen MN, Barrett PHR (2006) Factorial study of the effect of n-3 fatty acid supplementation and atorvastatin on the kinetics of HDL, apolipoproteins A-I and A-II in men with abdominal obesity. Am J Clin Nutr 84(1): 37-43.

39.Torrejon C, Jung UJ, Deckelbaum RJ (2007) n-3 Fatty acids and cardiovascular disease: actions and molecular mechanisms. PLEFA 77(5-6): 319-326.

40. Thomas T, Pfeiffer AF (2011) Foods for the prevention of diabetes: how do they work? Diabetes Metab Res Rev 28(1): 25-49.

41. Due A, Larsen TM, Hermansen K, Stender S, Holst JJ, et al. (2008) Comparison of the effects on insulin resistance and glucose tolerance of 6-mo high-monounsaturated-fat, low-fat, and control diets. Am J Clin Nutr 87(4): 855-862.

42. Riserus U, Willett WC, Hu FB (2009) Dietary fats and prevention of type 2 diabetes. Prog Lipid Res 48(1): 44- 51.

43. Rasic-Milutinovic Z, Perunicic G, Pljesa S, Gluvic Z, Sobajic S, et al. (2007) Effects of N-3 PUFAs supplementation on insulin resistance and inflammatory biomarkers in hemodialysis patients. Ren Fail 29(3): 321-329.

44. De Caterina R, Madonna R, Bertolotto A, Schmidt EB (2007) n-3 fatty acids in the treatment of diabetic patients: biological rationale and clinical data. Diabetes Care 30(4): 1012-1026.

45. Forman BM, Chen J, Evans RM (1997) Hypolipidemic drugs, polyunsaturated fatty acids, and eicosanoids are ligands for peroxisome proliferatoractivated receptors alpha and delta. Proc Natl Acad Sci USA 94(9): 4312- 4317.

46. Kahn SE, Hull RL, Utzschneider KM (2006) Mechanisms linking obesity to insulin resistance and type 2 diabetes. Nature 444: 840-846.

47. Flachs P, Rossmeisl M, Bryhn M, Kopecky J (2009) Cellular and molecular effects of n-3 polyunsaturated fatty acids on adipose tissue biology and metabolism. Clin Sci 116(1): 1-16.

48. Okuno M, Kajiwara K, Imai S, Kobayashi T, Honma N, et al. (1997) Perilla oil prevents the excessive growth of visceral adipose tissue in rats by down-regulating adipocyte differentiation. J Nutr 127(9): 1752-1757.

49. Ailhaud G, Massiera F, Weill P, Legrand P, Alessandri JM, et al. (2006) Temporal changes in dietary fats: role of $n-6$ polyunsaturated fatty acids in excessive adipose tissue development and relationship to obesity. Prog Lipid Res 45(3): 203-236.

50. Madsen L, Pedersen LM, Liaset B, Ma T, Petersen RK, et al. (2008)
cAMP-dependent Signaling Regulates the Adipogenic Effect of n-6 Polyunsaturated Fatty Acids. J Biol Chem 283(11): 7196-7205.

51. Calder PC (2013) Omega-3 polyunsaturated fatty acids and inflammatory processes: nutrition or pharmacology? $\mathrm{Br} \mathrm{J}$ Clin Pharmacol 75(3): 645-662.

52. Vucic V (2013) The role of dietary polyunsaturated fatty acids in inflammation. Serb J Clin Exp Res 14 (3): 93-99.

53.Vučić V, Ristić-Medić D (2012) Eicosapentaenoic Acid: The Role in Malignant Diseases. In Eicosapentaenoic Acid: Sources, Health Effects and Role in Disease Prevention. Theodore G. Bradley and Francisco P. Vargas (Editors). Nova Science Publishers Inc.

54.Gagnon L, Filion LG, Dubois C, Rola-Pleszczynski M (1989) Leukotrienes and macrophage activation: augmented cytotoxic activity and enhanced interleukin 1, tumor necrosis factor and hydrogen peroxide production. Agents Actions 26: 141-147.

55. Kunkel SL, Spengler M, May MA, Spengler R, Larrick J, et al. (1988) Prostaglandin E2 regulates macrophage-derived tumor necrosis factor gene expression. J Biol Chem 263(11): 5380-5384.

56. Weaver KL, Ivester P, Seeds M, Case LD, Arm JP, et al. (2009) Effect of dietary fatty acids on inflammatory gene expression in healthy humans. J Biol Chem 284(23): 15400-15407.

57. Plomgaard P, Nielsen AR, Fischer CP, Mortensen OH, Broholm C, et al. (2007) Associations between insulin resistance and TNF-alpha in plasma, skeletal muscle and adipose tissue in humans with and without type 2 diabetes. Diabetologia 50(12): 2562-2571.

58. Ruan H, Lodish HF (2003) Insulin resistance in adipose tissue: direct and indirect effects of tumor necrosis factor-alpha. Cytokine Growth Factor Rev 14(5): 447-455.

59. Calder PC (2002) Dietary modification of inflammation with lipids. Proc Nutr Soc 61(3): 345-358.

60. Mantzioris E, Cleland LG, Gibson RA, Neumann MA, Demasi M, et al. (2000) Biochemical effects of a diet containing foods enriched with n-3 fatty acids. Am J Clin Nutr 72(1): 42-48.

61. Ferrucci L, Cherubini A, Bandinelli S, Bartali B, Corsi A, et al. (2006) Relationship of plasma polyunsaturated fatty acids to circulating inflammatory markers. J Clin Endocrinol Metab 91(2): 439-446.

62. Hall WL (2009) Dietary saturated and unsaturated fats as determinants of blood pressure and vascular function. Nutr Res Rev 22(1): 18-38.

63. Simon JA, Fong J, Bernert JT Jr (1996) Serum fatty acids and bload preasure. Hypertension 27(2): 303-307.

64. Morris MC, Sacks F, Rosner B (1993) Does fish oil lower blood pressure? A meta-analysis of controlled trials. Circulation 88(2): 523533.

65. McGiff JC, Quilley J (2001) 20-Hydroxyeicosatetraenoic acid and epoxyeicosatrienoic acids and blood pressure. Curr Opin Nephrol Hypertens 10(2): 231-237.

66. Geleijnse JM, Giltay EJ, Grobbee DE, Donders AR, Kok FJ (2002) Blood pressure response to fish oil supplementation: metaregression analysis of randomized trials. J Hypertens 20(8): 1493-1499.

67. Das UN (2004) Long-chain polyunsaturated fatty acids interact with nitric oxide, superoxide anion, and transforming growth factor-beta to prevent human essential hypertension. Eur J Clin Nutr 58(2): 195203.

68. Ristic Medic D, Ristic V, Arsic A, Postic M, Ristic G, et al. (2006) Effects of soybean D-LeciVita product on serum lipids and fatty acid 
composition in type 2 diabetic patients with hyperlipidemia. Nutr Metab Cardiovasc Dis 16(6): 395-404.

69. Vessby B, Gustafsson IB, Tengblad S, Boberg M, Andersson A (2002) Desaturation and elongation of Fatty acids and insulin action. Ann N Y Acad Sci 967:183-195.

70. Dobrzyn A, Ntambi JM (2004) The Role of Stearoyl-CoA Desaturase in Body Weight Regulation. Trends Cardiovasc Med 14(2):77-81.

71. Ntambi JM, Miyazaki M, Stoehr JP, Lan H, Kendziorski CM, et al. (2002) Loss of stearoyl-CoA desaturase- 1 function protects mice against adiposity. Proc Natl Acad Sci USA 99(17): 11482-11486.

72. Riccardi G, Giacco R, Rivellese AA (2004) Dietary fat, insulin sensitivity and the metabolic syndrome. Clin Nutr 23(4): 447-456.

73. Sampath H, Miyazaki M, Dobrzyn A, Ntambi JM (2007) Stearoyl-CoA
Desaturase-1 Mediates the Pro-lipogenic Effects of Dietary Saturated Fat. J Biol Chem 282: 2483-2493.

74.Vessby B (2003) Dietary fat, fatty acid composition in plasma and the metabolic syndrome. Curr Opin Lipidol 14(1): 15-19.

75.Warensjö E, Öhrvall M, Vessby B (2006) Fatty acid composition and estimated desaturase activities are associated with obesity and lifestyle variables in men and women. Nutr Metab Cardiovasc Dis 16(2): 128-136.

76. Laaksonen DE, Lakka TA, Lakka HM, Nyyssonen K, Rissanen T, et al. (2002) Serum fatty acid composition predicts development of impaired fasting glycaemia and diabetes in middle aged men. Diabet Med 19(6): 456-464. 